\title{
Clinical and epidemiological features of heart-hand syndrome, an updated analysis in China
}

\author{
Yaobin Yin ${ }^{1 \dagger}$, Jianguang $\mathrm{Ji}^{2,3 \dagger}$, Junhui Zhao ${ }^{1}$, Shanlin Chen ${ }^{1 * \dagger}$ and Wen $\operatorname{Tian}^{1{ }^{* \dagger}} \mathbb{C}$
}

\begin{abstract}
Background: The purpose of this study was to prospectively recruit patients treated with limb malformation and to explore the prevalence and the clinical and epidemiological features of Heart-Hand Syndrome (HHS) in China.

Methods: The consecutive patients treated for congenital upper limb malformation in Beijing Ji Shui Tan Hospital from October 1st, 2016 to October 1st, 2019 were prospectively recruited. We reviewed the patients' medical records and identified patients with abnormal electrocardiogram (ECG) and/or abnormal ultrasonic cardiogram as well as their basic demographic and clinical characteristics.

Results: A total 1653 (1053 male and 600 female) patients with congenital upper extremity malformations were prospectively recruited. Among them, 200 (12.1\%) had abnormal ultrasonic cardiogram (181 patients, 10.9\%) and/or abnormal ECG (19 patients, 1.1\%). The commonest type of abnormal heart structure was atrial septal defect (69/181 $38.1 \%)$, and the commonest abnormal ECG was wave patterns (7/19, 36.8\%). HHS patients had a higher comorbidity rate (11\%) than non-HHS patients (6.9\%). Patients with HHS were classified into four groups by the types of congenital upper extremity malformations, among which the most common group was thumb type (121/200, $60.5 \%)$.

Conclusions: HHS occurred frequently among patients with congenital upper extremity malformation in China, particularly for those with multiple congenital malformations. The commonest type of hand malformations of HHS patients was thumb malformation.
\end{abstract}

Keywords: Heart-hand syndrome (HHS), Congenital malformations, Clinical epidemiology, Classification

\section{Background}

Heart-hand syndrome (HHS) is characterized by the cooccurrence of a limb malformation and a congenital cardiac disease, presenting with substantial clinical and genetic heterogeneity [1]. HHS is a broad category of diseases which might be included in many different syndromes, such as the vertebral abnormalities, anal atresia,

\footnotetext{
* Correspondence: drcsI586@163.com; wentiansyz@163.com

'Yaobin Yin, Jianguang Ji shared the first arthorship, Shanlin Chen and Wen Tian contributed equally to this work.

'Department of Hand Surgery, Beijing Ji Shui Tan Hospital, Xin jie kou dong jie 31, Xi Cheng Qu, Beijing 100035, China

Full list of author information is available at the end of the article
}

cardiac abnormalities, tracheoesophageal fistula and/or esophageal atresia, renal agenesis and dysplasia, and limb defect syndrome (VACTERL syndrome) [2], the "longthumb" brachydactyly syndrome [3], thrombocytopeniaabsent radius syndrome(TRS) [4], the Fanconi anemia syndrome [5], et al. Most congenital upper extremity malformations require surgical treatment, it is thus necessary to have a full understanding of the potential complications, such as simultaneous congenital heart disease, during anesthesia and operation.

As the mandatory policy of pre-marital medical examination has stopped and the one-child policy has been

(C) The Author(s). 2020 Open Access This article is licensed under a Creative Commons Attribution 4.0 International License, which permits use, sharing, adaptation, distribution and reproduction in any medium or format, as long as you give appropriate credit to the original author(s) and the source, provide a link to the Creative Commons licence, and indicate if changes were made. The images or other third party material in this article are included in the article's Creative Commons licence, unless indicated otherwise in a credit line to the material. If material is not included in the article's Creative Commons licence and your intended use is not permitted by statutory regulation or exceeds the permitted use, you will need to obtain permission directly from the copyright holder. To view a copy of this licence, visit http://creativecommons.org/licenses/by/4.0/. The Creative Commons Public Domain Dedication waiver (http://creativecommons.org/publicdomain/zero/1.0/) applies to the data made available in this article, unless otherwise stated in a credit line to the data. 
ended in China recently, the number of patients with congenital upper extremity malformation has been increased as a consequence of the changed policies [6]. In our previous retrospective study, we found that the prevalence of HHS was around $11.8 \%$ among 1462 patients treated with congenital upper extremity malformations [7]. In light of the increased number of patients with congenital upper extremity malformation in China, we expected that more HHS cases might be diagnosed in Chinese patients. We thus planned this cohort study and aimed (1) to prospectively recruit patients with congenital upper extremity malformation and explore the prevalence of HHS, (2) to update the characteristics and the clinical features of HHS in China, (3) to make a new classification for HHS based on the clinical characteristics of hand malformations as previous classifications of HHS do not meet the need of HHS patients in China.

\section{Methods}

The Ethics Committee at Beijing Ji Shui Tan Hospital approved this study. All methods were carried out in accordance with relevant regulations and guidelines, and written consent to participate was obtained from the parents/guardians of the children included in this study (children are considered anyone under the age of 16).

Beijing Ji Shui Tan Hospital is a national orthopedics center in China. All the patients treated for congenital upper extremity malformation in this hospital between October 1st, 2016 and October 1st, 2019 were prospectively recruited in this study. The medical records and the results of electrocardiogram (ECG) and ultrasonic cardiogram were reviewed separately by two clinicians. Patients with abnormal ECG and/or abnormal ultrasonic cardiogram were identified.

We further classified upper extremity malformation according to the Swanson upper extremity malformation classification [8], and analyzed the proportion of HHS for each type of upper extremity malformation. We also analyzed the different abnormal ultrasonic cardiogram and ECG for each type of upper extremity malformations. We explored the correlation of HHS with the blood type and comorbidity among patients with upper extremity malformations. We further made a new classification of HHS based on the type of hand malformations among Chinese patients.

\section{Statistics}

Descriptive data were presented as number and percentage for the categorical variables. $P$ value was examined using chi-square test for categorical variables. SAS version 9.2 (SAS Institute, Cary, NC, USA) was used for statistical analyses.

\section{Results}

A total 1653 (1053 male and 600 female) patients with congenital upper extremity malformations were recruited and treated in the Hand Surgery Department of Beijing Ji Shui Tan Hospital between October 1st, 2016, and October 1st, 2019 (Table 1). Among them, duplication (type III Swanson upper extremity malformation classification) was the most common type. Blood samples were available for 884 patients. Except for congenital cardiac disease, 122 patients (7.4\%) were diagnosed with other comorbidities and the lower extimity malformations were the most common.

There were 200 patients $(200 / 1653)$ who met the clinical diagnosis criteria of HHS. One hundred eighty-one patients had abnormal heart structure and 19 patients only had abnormal ECG. In Table 2 we present the distribution of various congenital cardiac diseases among different types of upper limb malformations. There was a significant difference for congenital cardiac disease among the different types of upper limb malformations $(p<0.05)$. Type I Swanson upper extremity malformation classification had the highest prevalence of congenital cardiac diseases. The commonest type of abnormal heart structure was atrial septal defect $(69 / 181,38.1 \%)$, followed by tricuspid regurgitation $(65 / 181,36.9 \%)$. The commonest abnormal result of ECG was abnormal wave patterns $(7 / 19,36.8 \%)$.

In Table 3, we present the distribution of blood type among patients with congenital upper limb malformations and the prevalence of HHS. Patients with blood type B had the highest prevalence of HHS (13.4\%), but there was no significant difference among different blood types.

In Table 4, we analyzed the distribution of different comorbidities among patients with congenital upper limb malformations stratified by HHS diagnosis. HHS patients had a higher rate of comorbidity (11\%) than non-HHS patients $(6.9 \%)(P<0.05)$.

According to our patients, we made a new classification of HHS based on the malformations of the hand. The new classification included a total of 4 types: thumb type, finger type, contracture type, and rare type, as shown in Table 5. The commonest type was thumb type, which accounted for $60.5 \%$ of patients with HHS.

\section{Discussion}

In this prospective cohort study, we identified a total of 1653 patients with congenital upper extremity malformations.We found that the prevalence of HHS was $12.1 \%$, which showed a similar result as in our previous retrospective study [7]. Type I congenital upper limb malformations (Failure of formation of parts) was most likely to present with congenital cardiac disease, which was also in line with the result of our previous study. In 
Table 1 Basic demographic and clinical characteristics among patients treated with congenital upper limb malformation

\begin{tabular}{|c|c|c|}
\hline Characteristic & Number & $\%$ \\
\hline Total & 1653 & 100.0 \\
\hline \multicolumn{3}{|l|}{ Age } \\
\hline $0-4$ & 1328 & 80.3 \\
\hline $5-9$ & 202 & 12.3 \\
\hline $10+$ & 123 & 7.4 \\
\hline Median & 2 & \\
\hline \multicolumn{3}{|l|}{ Gender } \\
\hline Male & 1053 & 63.7 \\
\hline Female & 600 & 36.3 \\
\hline \multicolumn{3}{|l|}{ Hand abnormality } \\
\hline I Failure of formation of parts (arrest of development) & 70 & 4.2 \\
\hline II Failure of differentiation (separation) of parts & 537 & 32.5 \\
\hline III Duplication & 921 & 55.7 \\
\hline IV Overgrowth & 10 & 0.6 \\
\hline V Undergrowth & 79 & 4.8 \\
\hline VI Congenital constriction band syndrome & 36 & 2.2 \\
\hline \multicolumn{3}{|l|}{ Blood type } \\
\hline A & 260 & 15.7 \\
\hline B & 276 & 16.7 \\
\hline $\mathrm{O}$ & 262 & 15.8 \\
\hline$A B$ & 86 & 5.2 \\
\hline Missing & 769 & 46.5 \\
\hline Comorbidity except for heart & 122 & 7.4 \\
\hline Toes malformation & 77 & 4.7 \\
\hline Ankle malformation & 16 & 1.0 \\
\hline Knee malformation & 5 & 0.3 \\
\hline Hip malformation & 4 & 0.2 \\
\hline Spine malformation & 5 & 0.3 \\
\hline Facial malformation & 10 & 0.6 \\
\hline Thoracic malformation & 2 & 0.1 \\
\hline Kidney malformation & 2 & 0.1 \\
\hline Anemia & 1 & 0.1 \\
\hline
\end{tabular}

this study, $60.5 \%$ of HHS patients had thumb malformations, similar to what we found in the previous study (69.2\%). Some studies have shown that the thumb is remarkably different from the other four digits and developed in a different molecular environment, which provides the underlying mechanisms for the strong association between thumb malformations and HHS $[9,10]$, suggesting that genes related to thumb formation might be related to HHS.

Our previous study was based on patients treated with upper extremity malformations from October 1st, 2013 to October 1st, 2016 in the same hospital. The number of beds and surgeons in this hospital did not change after the previous study. However, the number of patients who were treated with upper extremity was increased by $13 \% \quad((1653-1462) / 1462=0.13)$. The underlying reasons are not clear as we did not find a change of the referral pattern of patients and and no therapeutic centers nearby were closed. This phenomenon may be related to the Chinese policy changed from "One family, one child" to "one family, two children". The increased rate of upper extremity malformations might be due to the increased number of elderly pregnant women associated with this policy change [11].

HHS is well documented since first reported by Kato in 1924 [12]. It has been reported by many others 
Table 2 Prevalence of congenital heart defect stratified by different hand abnormality

\begin{tabular}{|c|c|c|c|c|c|c|c|}
\hline Characteristic & $\begin{array}{l}\text { I Failure of formation } \\
\text { of parts (arrest of } \\
\text { development }\end{array}$ & $\begin{array}{l}\text { II } \\
\text { Failure of } \\
\text { differentiation } \\
\text { (separation) }\end{array}$ & $\begin{array}{l}\text { III } \\
\text { Duplication }\end{array}$ & $\begin{array}{l}\text { IV } \\
\text { Overgrowth }\end{array}$ & $\begin{array}{l}\text { V } \\
\text { Undergrowth }\end{array}$ & $\begin{array}{l}\text { VI } \\
\text { Congenital } \\
\text { constriction } \\
\text { band syndrome }\end{array}$ & Total \\
\hline No. patient & 70 & 537 & 921 & 10 & 79 & 36 & 1653 \\
\hline No. congenital heart defect & 18 & 60 & 103 & 0 & 13 & 6 & 200 \\
\hline$\%$ & 25.7 & 11.2 & 11.2 & 0.0 & 16.5 & 16.7 & 12.1 \\
\hline Atrial septal defect & 7 & 16 & 43 & 0 & 2 & 1 & 69 \\
\hline Ventricular septal defect & 3 & 1 & 6 & 0 & 0 & 0 & 10 \\
\hline Multiple valve regurgitation & 1 & 4 & 2 & 0 & 1 & 0 & 8 \\
\hline Patent ductus arteriosus & 0 & 2 & 4 & 0 & 1 & 2 & 9 \\
\hline Mitral regurgitation & 1 & 0 & 4 & 0 & 1 & 1 & 7 \\
\hline Tricuspid regurgitation & 2 & 27 & 32 & 0 & 3 & 1 & 65 \\
\hline Aortic valve regurgitation & 0 & 1 & 2 & 0 & 0 & 0 & 3 \\
\hline Persistent left superior vena cava & 2 & 1 & 2 & 0 & 1 & 1 & 7 \\
\hline Tetralogy of Fallot & 0 & 0 & 1 & 0 & 0 & 0 & 1 \\
\hline Pulmonary artery sling & 0 & 0 & 1 & 0 & 0 & 0 & 1 \\
\hline Pulmonary stenosis & 0 & 1 & 0 & 0 & 0 & 0 & 1 \\
\hline Conduction block & 2 & 1 & 1 & 0 & 1 & 0 & 5 \\
\hline Abnormal wave patterns & 0 & 4 & 1 & 0 & 2 & 0 & 7 \\
\hline Premature beat & 0 & 2 & 2 & 0 & 1 & 0 & 5 \\
\hline Tachycardia. & 0 & 0 & 2 & 0 & 0 & 0 & 2 \\
\hline$P$ value & 0.009 & & & & & & \\
\hline
\end{tabular}

subsequently $[13,14]$. HHS includes the most common type - HHS I: Holt-Oram syndrome [13] (congenital heart disease and radial ray anomalies) and several rare types - HHS II: Tabatznik syndrome (arrhythmias and brachytelephalangy) [15], HHS III: Spanish type (arrhythmia and brachydactyly type C) [16], and a potential HHS IV: Slovenian type (arrhythmia, dilated cardiomyopathy, and brachydactyly) [17]. However, there were only 16 patients $(8 \%)$ in this study who could be classified according to previous classifications. These $16 \mathrm{pa}-$ tients met the clinical diagnosis of Holt-Oram syndrome. ASD (7 patients, 44\%) was the commonest cardiovascular anomaly for these patients, the rate of which was lower than that of the study reported by Wall, L.B. (ASD 53\%) [18].

Table 3 Prevalence of congenital heart defect stratified by different blood type

\begin{tabular}{lllll}
\hline Blood type & Total & HHS & $\%$ & $P$ value \\
\hline A & 260 & 33 & 12.7 & 0.94 \\
B & 276 & 37 & 13.4 & \\
O & 262 & 30 & 11.5 & \\
AB & 86 & 10 & 11.6 & \\
Missing & 769 & 90 & 11.7 & \\
Total & 1653 & 200 & 12.1 & \\
\hline
\end{tabular}

Most HHS patients in this study could not be classified according to current knowledge, suggesting that there might be ethnic variance of HHS. It is thus necessary to create a new classification for HHS in China. According to the clinical characteristics of these patients, we made a new classification. This new classification was based on the malformations of the hand and could be used easily. The commonest type of hand malformations of HHS patients in this study was related to thumb malformation (121, 60.5\%), including thumb hypoplasia, thumb duplication, triphalangeal thumb, et al. Lam et al. found that preaxial polydactyly (thumb duplication) and

Table 4 Prevalence of HHS and non-HHS stratified by comorbidity

\begin{tabular}{|c|c|c|c|c|c|}
\hline \multirow[t]{2}{*}{ Comorbidity } & \multicolumn{2}{|l|}{ HHS } & \multicolumn{2}{|c|}{ Non-HHS } & \multirow[t]{2}{*}{$P$ value } \\
\hline & No. & $\%$ & No. & $\%$ & \\
\hline Lower extremity malformation & 15 & 7.5 & 87 & 6.0 & \\
\hline Spine malformation & 2 & 1.0 & 3 & 0.2 & \\
\hline Facial malformation & 3 & 1.5 & 7 & 0.5 & \\
\hline Thoracic malformation & 0 & 0.0 & 2 & 0.1 & \\
\hline Kidney malformation & 2 & 1.0 & 0 & 0.0 & \\
\hline Anemia & 0 & 0.0 & 1 & 0.1 & \\
\hline Total & 22 & 11.0 & 100 & 6.9 & 0.001 \\
\hline
\end{tabular}


Table 5 HHS classification according to the hand malformations

\begin{tabular}{|c|c|c|c|}
\hline \multirow[t]{2}{*}{ Type } & \multicolumn{2}{|c|}{ Subtype $^{a}$} & \multirow[b]{2}{*}{$\%$} \\
\hline & a & b & \\
\hline Type1 Thumb type (thumb hypoplasia, thumb duplication, triphalangeal thumb, et al) & 113 & 8 & $60.5 \%$ \\
\hline Type2 Finger type (syndactyly, brachydactyly, symbrachydactyly, et al) & 45 & 8 & $26.5 \%$ \\
\hline Type3 Contracture type (single or multiple congenital joint contractures) & 22 & 3 & $12.5 \%$ \\
\hline Type4 Rare type (could not classify into malformations mentioned above) & 1 & 0 & $0.5 \%$ \\
\hline
\end{tabular}

${ }^{a}$ Subtype a: an abnormal heart structure was discovered by ultrasonic cardiogram, associated with normal EGC or abnormal ECG. Subtype b: only abnormal result of ECG was discovered

forearm radial deficiencies may share a common developmental origin [19]. So, we put all malformations related to thumb into one type. The second type $(53,26.5 \%)$ is related to malformations including syndactyly, brachydactyly, and symbrachydactyly. This type included previous HHS II, HHS III, and HHS IV. The third type was related to congenital contractures (25 12.5\%). Joint movement limitations in HHS might be considered close to the classical joint contractures observed in Emery-Dreifuss muscular dystrophy, which was LMNA generelated disease [20]. Renou et al. reported an intronic LMNA mutation that co-segregated with the HHS clinical features [17]. The fourth type included other hand malformations except for the malformations mentioned above. This new classification based on clinical characteristics is easy to use and could cover all of the HHS patients in this study. However, we cannot identify the molecular causes regarding different subcategories based on current evidence and further studies are higher needed.

We analyzed the distribution of blood types of HHS patients. Blood type $\mathrm{B}$ had the highest morbidity rate (13.4\%), but there was no significant difference between blood types. We need further research on this field because around half of the patients did not attend blood type test. Further studies with enough samples are needed to explore the association of HHS with blood type in detail. The gene related to $\mathrm{ABO}$ type has been identified and resides on chromosome 9 at the band 9q34. 2 with 7 exons, it is thus higher possible to identify the underlying genes of HHS based on genetic linkage analyses if we can observe the association between specific blood type with HHS. In this study, 122 patients $(7.4 \%)$ had comorbidity conditions except for the heart. The lower extremity malformations were the commonest. HHS patients had a much higher morbidity rate $(11 \%)$ than non-HHS patients $(6.9 \%) \quad(P<0.05)$. The comorbidity conditions were reported previously $[21,22]$, but this is the first time to report the morbidity rate for HHS. It is highly necessary to inform patients who had multiple congenital malformations because the prevalence of HHS was higher than that with only upper extremity malformations.

There were a few limitations in this study. First, all the patients were recruited from the hand surgery department in one Chinese national orthopedics center, which might not be a comprehensive representative of the Chinese population. In addition, the classification that we proposed in this study needs to be confirmed by other studies.

\section{Conclusions}

In summary, the prevalence of HHS among patients with congenital upper extremity malformations is relatively high in China, especially for patients with multiple congenital malformations. The commonest type of hand malformations of HHS patients was related to thumb malformation.

\section{Acknowledgements}

We would like to thank Xiuping Cai and Jie Shen for their help for the collection of the data.

\section{Authors' contributions}

YB Y and JG J had directly participated in the planning, execution, and analysis of the study. JH Z had reviewed the patients' medical record. SL C and W T had participated in the planning the study. The author(s) read and approved the final manuscript.

\section{Funding}

Yaobin Yin had received funding from Bei jing Ji Shui Tan Hospital Nova Program (XKXX201615). Wen Tian received funding form The National Key Research and Development Program of China (No. 2016YFC0901500).

\section{Availability of data and materials}

The datasets used and/or analysed during the current study are available from the corresponding author on reasonable request.

\section{Ethics approval and consent to participate}

The ethical committee in Beijing Ji Shui Tan Hospital approved this study. All methods were carried out in accordance with relevant guidelines and regulations, and written consent to participate was obtained from the parents/guardians of the minors included in this study (minors are considered anyone under the age of 16 ).

\section{Consent for publication}

Not applicable.

\section{Competing interests}

There are no competing financial interests.

\section{Author details}

'Department of Hand Surgery, Beijing Ji Shui Tan Hospital, Xin jie kou dong jie 31, Xi Cheng Qu, Beijing 100035, China. ${ }^{2}$ Center for Primary Health Care Research, Lund University, Malmö, Sweden. ${ }^{3}$ Clinical Research Centre (CRC), Skåne University Hospital, Building 28, floor 11, Jan Waldenströms gata 35, SE-205 02 Malmö, Sweden. 
Received: 20 April 2020 Accepted: 19 November 2020

Published online: 25 November 2020

\section{References}

1. Basson CT, Solomon SD, Weissman B, MacRae CA, Poznanski AK, Prieto F, de la Ruiz FS, Pease WE, Levin SE, Holmes LB. Genetic heterogeneity of hearthand syndromes. Circulation. 1995;91(5):1326-9.

2. Solomon BD. The etiology of VACTERL association: current knowledge and hypotheses. Am J Med Genet C Semin Med Genet. 2018;178(4):440-6.

3. Hollister DW, Hollister WG. The "long-thumb" brachydactyly syndrome. Am J Med Genet. 1981;8(1):5-16.

4. Elmakky A, Stanghellini I, Landi A, Percesepe A. Role of genetic factors in the pathogenesis of radial deficiencies in humans. Curr Genomics. 2015; 16(4):264-78.

5. Fiesco-Roa MO, Giri N, McReynolds L, Best AF, Alter BP. Genotypephenotype associations in Fanconi anemia: a literature review. Blood Rev. 2019;37:100589.

6. Qian WQW, Liang F, Kuikui H, Yang Y, Zhilan L. Birth defects and mortality trends during the inatal period in Lanzhou City. Chin J Reprod Heal. 2016;27(5):420-3.

7. Yin Y, Ji J, Borne Y, Wang Y, Zhao J, Chen S, Tian W. Clinical and epidemiological features of heart-hand syndrome: a hospital-based study in China. Sci Rep. 2018;8(1):8469.

8. Swanson AB, Swanson GD, Tada K. A classification for congenital limb malformation. J Hand Surg. 1983;8(5 Pt 2):693-702.

9. Oberg KC, Feenstra JM, Manske PR, Tonkin MA. Developmental biology and classification of congenital anomalies of the hand and upper extremity. J Hand Surg Am. 2010;35(12):2066-76.

10. Oberg KC. Review of the molecular development of the thumb: digit primera. Clin Orthop Relat Res. 2014;472(4):1101-5.

11. Fang L. Analysis on high-risk factors and clinical interventions for senile pregnant women after the implementation of two-child policy. China Med Pharmacy. 2019;22(9):95-8.

12. Kato K. Congenital absence of the radius with review of the literature and report of three cases. J Bone Joint Surg. 1924;6(43):589-626.

13. Vanlerberghe $C$, Jourdain AS, Ghoumid J, Frenois F, Mezel A, Vaksmann G, Lenne B, Delobel B, Porchet N, Cormier-Daire V, et al. Holt-Oram syndrome: clinical and molecular description of 78 patients with TBX5 variants. Eur J Hum Genet. 2019:27(3):360-8.

14. Kumar B, Agstam S. Holt-Oram syndrome: hands are the clue to the diagnosis. Int J Appl Basic Med Res. 2019;9(4):248-50.

15. Silengo MC, Biagioli M, Guala A, Lopez-Bell G, Lala R. Heart-hand syndrome II. A report of Tabatznik syndrome with new findings. Clin Genet. 1990;38(2):105-13.

16. Ruiz De La Fuente S, Prieto F. Heart-hand syndrome. III. A new syndrome in three generations. Hum Genet. 1980;55(1):43-7.

17. Renou L, Stora S, Yaou RB, Volk M, Sinkovec M, Demay L, Richard P, Peterlin B, Bonne G. Heart-hand syndrome of Slovenian type: a new kind of laminopathy. J Med Genet. 2008;45(10):666-71.

18. Wall LB, Piper SL, Habenicht R, Oishi SN, Ezaki M, Goldfarb CA. Defining features of the upper extremity in Holt-Oram syndrome. J Hand Surg. 2015; 40(9):1764-8.

19. Lam WL, Oh JDH, Johnson EJ, Pertinez SP, Stephens C, Davey MG. Experimental evidence that preaxial polydactyly and forearm radial deficiencies may share a common developmental origin. J Hand Surg Eur Vol. 2019;44(1):43-50.

20. Broers JL, Ramaekers FC, Bonne G, Yaou RB, Hutchison CJ. Nuclear lamins: laminopathies and their role in premature ageing. Physiol Rev. 2006;86(3): 967-1008.

21. Demura M, Yoneda T, Karashima S, Higashikata T, Mabuchi H, Kawano M, Yamagishi M, Takeda Y. A possible new syndrome with double endocrine tumors in association with an unprecedented type of familial heart-hand syndrome: a case report. J Med Case Rep. 2010;4:347.

22. Saura D, Campos JV, Villegas M, Pico F, de la Morena G, Valdes-Chavarri M. Heart-hand syndrome. Int J Cardiol. 2008;129(1):e7-9.

\section{Publisher's Note}

Springer Nature remains neutral with regard to jurisdictional claims in published maps and institutional affiliations.

\section{Ready to submit your research? Choose BMC and benefit from:}

- fast, convenient online submission

- thorough peer review by experienced researchers in your field

- rapid publication on acceptance

- support for research data, including large and complex data types

- gold Open Access which fosters wider collaboration and increased citations

- maximum visibility for your research: over $100 \mathrm{M}$ website views per year

At BMC, research is always in progress.

Learn more biomedcentral.com/submissions 